\title{
Voices from the Front Lines: An Analysis of Physicians' Reflective Narratives about Flaws with the 'System'
}

\author{
Tracy Moniz ${ }^{1}$ (D) $\cdot$ Rachael Pack ${ }^{2} \cdot$ Lorelei Lingard $^{3} \cdot$ Chris Watling $^{2}$
}

Accepted: 5 March 2021 / Published online: 6 April 2021

(C) The Author(s), under exclusive licence to Springer Science+Business Media, LLC, part of Springer Nature 2021

\begin{abstract}
Physicians often express frustration with the 'system' in which they work. Over time, this frustration may put them at risk of burnout and disengagement, which may impact patient care. In this study, we aimed to understand the nature of the system flaws that physicians identified in their published narratives and to explore their self-representation as agents of change. We reviewed all reflective narratives published in four medical journals (NEJM, JAMA, CMAJ, Annals IM) between January 2015 and December 2017 ( $n=282)$. By consensus, we identified those that addressed system flaws $(n=87)$. Using content and narrative analysis, we analyzed the types of flaws and the physicians' orientation to the flawed system. We identified seven recurring system flaws-five related to medical culture: failures of communication, erosive impact of the hidden curriculum, inadequate health advocacy, frenzied pace of work, and experience of stigma. Less frequently, physicians' narratives also exposed limited and disparate healthcare resources and restrictive institutional practices as impeding patient-centered care. Physicians expressed agency to create change foremost when writing about flaws related to medical culture. While physicians are challenged by system flaws, they strive to practice in ways that do not succumb to them. We saw tension between the elements outside the physician's control and those within it. This tension becomes a source of distress when the compromises that emerge from system flaws move physicians away from the values that define their professional identity.
\end{abstract}

Keywords Physician narratives $\cdot$ Writing $\cdot$ Narrative analysis $\cdot$ Medical culture $\cdot$ System

Tracy Moniz

Tracy.Moniz@msvu.ca

1 Department of Communication Studies, Mount Saint Vincent University, 166 Bedford Hwy., McCain Centre, Room 305F, Halifax, Nova Scotia B3M 2J6, Canada

2 Centre for Education Research \& Innovation, Schulich School of Medicine \& Dentistry, Western University, London, Ontario, Canada

3 Centre for Education Research \& Innovation, and Department of Medicine, Schulich School of Medicine \& Dentistry, Western University, London, Ontario, Canada 


\section{Introduction}

Physicians frequently write stories about the challenges they experience and the lessons they learn in practicing medicine (Moniz, Lingard, and Watling 2017). Leading medical journals regularly publish these stories, offering space for physicians to share their experiences with peers. Physicians' narratives thus provide a rich source of data for understanding how physicians perceive the predominant concerns of the profession (124-5). In our earlier work, we analyzed physicians' written narratives broadly with a view to cataloguing both what physicians tended to write about and how they narrated those issues (124-5). Among our most intriguing findings was that system flaws were a frequent subject and that these stories were often narrated as laments-that is, expressions of frustration, sadness or regret (124). That physicians frequently wrote stories about their frustrations with the 'system' in which they work suggests that they face prominent and ongoing challenges in practicing medicine with potential implications on physician wellness (124). This finding demands further exploration because, over time, frustration with the 'system' may put physicians at risk of burnout (Shanafelt 2009, 1338; Shanafelt, Sloan, and Habermann 2003, 513-4).

Maslach and Leiter define burnout as a "psychological syndrome emerging as a prolonged response to chronic interpersonal stressors on the job" $(2016,103)$. They further identify three dimensions of this response: (1) overwhelming exhaustion (e.g., loss of energy, depletion, debilitation), (2) feelings of cynicism and detachment from the job (e.g., depersonalization, irritability, loss of idealism), and (3) a sense of ineffectiveness and lack of accomplishment (e.g., reduced capability or productivity, low morale, inability to cope) (103). Burnout may compromise the physician-patient relationship, such as through alack of physician empathy and professionalism and a loss of trust and satisfaction on the part of the patient, as well as the quality of patient care including increased medical errors and decreased patient adherence to medical recommendations (Shanafelt 2009, 1338; Shanafelt and Noseworthy 2017, 130-1; Shanafelt, Sloan, and Habermann 2003, 513-4). It may also compromise physician wellness with consequences including relationship breakdowns, substance abuse, depression, and suicidal ideation, or suicide (Dyrbye and Shanafelt 2011, 2009; Jennings and Slavin 2015, 1246; Shanafelt 2009, 1338; Shanafelt et al. 2015, 1605; Shanafelt and Noseworthy 2017, 130-1; Shanafelt, Sloan, and Habermann 2003, 513-4). Burnout is a widespread problem in the medical profession with global studies across medical and surgical specialties reporting that approximately one in three physicians is experiencing burnout (Shanafelt 2009, 1338). As an example, a national physician health survey by the Canadian Medical Association in 2018 found high levels of resilience (reported by $82 \%$ of participants), coupled with high levels of burnout (reported by more than one in four participants, with one in three screening positive for depression) (2018ab), "suggesting that the issue is broader than individual factors and extends to other systemic factors" (Canadian Medical Association 2018a).

Many factors contribute to physician burnout. Drawing on literature in this domain, Shanafelt and colleagues group factors contributing to burnout into seven dimensions: workload, efficiency and resources, flexibility and control over work, work-life integration, alignment of individual and organizational values, social support and community at work, and the degree of meaning derived from work (Shanafelt et al. 2016, 429; Shanafelt and Noseworthy 2017, 131). They further propose that each of these dimensions is influenced by individual factors (e.g., ability to prioritize, choice of specialty), work unit factors (e.g., call schedule, unit norms), organizational (e.g., collegiality, opportunities for professional 
development), and national factors (e.g., requirements for maintenance of certification, regulations that increase clerical work) (Shanafelt et al. 2016, 429; Shanafelt and Noseworthy 2017, 131). A better understanding of how individual and system factors interact around physician well-being is required if we are to make meaningful progress on burnout.

Research on factors contributing to physician burnout, while extensive, has important methodological limitations. Much literature probing influences on burnout draws on survey research (Campbell et al. 2001; Dyrbye et al. 2011; Shanafelt et al. 2002, 2015, 2016). First-person written narrative remains an overlooked source of data in this area, despite its increasing uptake among physicians and medical learners (Charon 2005; Charon and Hermann 2012; Johna, Woodward, and Patel 2014; Mann, Gordon, and Macleod 2009) and its unique ability to illuminate - for writer and researcher alike - their reflections on experience (Bruner 1986; Charon and Hermann 2012; Roscoe 2009). Charon defines narratives as "stories with a teller, a listener, a time course, a plot, and a point" (2006, 3). With respect to first-person written narrative, in particular, Charon and Hermann conceive of writing as "discovery"- as "how one reflects on one's experience" and as "perhaps the most forceful means by which one can render it visible and, hence, comprehensible" to both oneself and to others $(2012,6)$. Similarly, Roscoe notes that "writing enhances the sense-making process and may reveal themes and tensions that are not apparent in oral versions" $(2009,68)$. In this context of medicine and medical humanities scholarship, written narrative-and narrative generally - offer a way to gain insight into the meanings and interpretations that individual storytellers (i.e., patients and physicians) ascribe to their experiences (Charon 2012; Charon et al. 2017; Coulehan 2007; Frank 2013; Hunter 1993; Younie 2009).

Underlying the concept of narrative is the assumption that narrative is a human universal- "one if not the fundamental unit that accounts for human experience" (Pinnegar and Daynes 2007, 4). As Barthes wrote: “... under [its] almost infinite diversity of forms, narrative is present in every age, in every place, in every society; it begins with the very history of mankind and there nowhere is nor has been a people without narrative.... [N]arrative is international, transhistorical, transcultural: it is simply there, like life itself" (1977, 79). Inherent in this belief of the ubiquity and universality of narrative is the idea that, as humans, we are predisposed to "make sense of our experiences by placing them in the form of a story, and we share our stories in the service of collective sense-making" (Roscoe $2009,67)$. Abbott contends that "to tell a story is to try to understand it" $(2008,109)$, and he similarly describes narrative as "a universal tool for knowing as well as telling, for absorbing knowledge as well as expressing it. This knowledge, moreover, is not necessarily static. Narrative can be, and often is, an instrument that provokes active thinking and helps us work through problems, even as we tell about them or hear them being told" (10-12).

Scholars have debated the limitations of narrative and its role in medicine. Among the "dangers" in medical humanities' approach to narrative, Woods questions the "truth-value" of narrative - that is, to what extent we can trust an illness narrative to be a faithful account of events-and she critiques the tendency in narrative scholarship and practice to overlook the cultural and historical dimensions of narrative $(2011,74)$. Among its limitations, she also cites the tendency to promote narrative as "the mode of human self expression," and, moreover, one that has value and is considered 'good' as a response to illness (74). She argues that belief in a 'narrative self' promotes a model of the self "as an agentic, authentic, autonomous storyteller; as someone with unique insight into an essentially private and emotionally rich inner world; as someone who possesses a drive for storytelling, and whose stories reflect and (re)affirm a sense of enduring individual identity" (74). She challenges this assumption, maintaining that there are non-narrative people-those who lack "the propensity or orientation toward narrativity"-as well as non-narrative forms of 
self-expression, specifically photography, metaphor, and phenomenology (75-6). Woods calls on scholars in medical humanities to "denaturalise narrative, to acknowledge not only that different cultures (including familial, institutional and professional cultures) will tell and find meaningful different kinds of stories, but also, more fundamentally, that the attachment to and valorisation of narrativity is not universally shared" (76). For Woods, narrative is not, by default, oriented toward good, nor does illness require storytelling. She notes the potential for narrative to be harmful in contexts where stories become vehicles of oppression and self-delusion (as opposed to critique and self-empowerment) or where they (re)produce dominant (i.e., Western, middle-class) ways of being rather than critique taken-for-granted assumptions about illness (76). In direct response, McKechnie (2014) recognizes the complexity of narrative as a way of mediating the world-and one that has as much truth-value as any other form. She further posits that narrative takes many forms, including nonverbal expression; that narrative has value as a way of expressing or bearing witness to the illness experience; and that it is "so fundamental to meaning-making that it is not just required, it is an inherent human response to creative outputs we encounter" (120). McKechnie foregrounds the role of the receiver and the need for interpretation in any communicative exchange. Regardless of how individuals express their life stories, be it as a written story or a photo, McKechnie maintains that it still requires a narrative response from the recipient. She writes: "Each time we make an effort to produce an expression of suffering, we demand a cognitive engagement that requires the ordering [of] information into narrative. We seek out communication; we desire transmission of an idea. This is narrativity, and it takes a myriad of forms" (123). Narrative is not without its limitations or complexities; however, it is pervasive and privileged in the medical humanities, both as a path to meaning-making and as a lens on understanding lived experience.

We approach our research from the position that narrative is a valuable mode of selfexpression in medicine and that, by engaging with narratives, we can come to grasp the meanings and interpretations that individual storytellers ascribe to their experiences. We view narrative as providing a distinct "mode of thinking"- "of ordering experience, of constructing reality" (Bruner 1986, 13) that is rooted in "the particulars of experience located in time and place" and in specific cultural contexts (Martin 2007, 49). The stories that physicians and medical learners choose to write and share with the medical community have potential to uncover new insights into what physicians perceive as flawed about the health systems they practice within and, moreover, what they think they can do about it. In this study, we therefore aimed to understand the nature of the system flaws that physicians most often identified in their narratives and to explore their sense of self as agents of change.

\section{Method}

We read all 282 first-person narratives published in four major international medical journals - the Journal of the American Medical Association ("A Piece of My Mind"), the New England Journal of Medicine ("Perspective"), the Annals of Internal Medicine ("On Being a Doctor"), and the Canadian Medical Association Journal ("Encounters")—between January 2015 and December 2017 to capture a broad spectrum of topics and views. By consensus, we identified those narratives that addressed system flaws $(n=87)$. We looked for stories written by physicians and medical learners that addressed a problem needing change. We included narratives where the flaw was central, not tangential, to the event 
narrated. To be included, the system flaw drove the story and was integral to the plot, like the main character of a story. We were guided, in our selection of narratives, by the World Health Organization's definition of "health system" as "all organizations, people and actions whose primary intent is to promote, restore or maintain health" - that is, service delivery; health workforce; health information systems; medical products, vaccines and technologies; health systems financing; and leadership and governance (2007, vi). However, in reviewing narratives for inclusion, we recognized that, while the World Health Organization's definition was broad enough to include physicians and the culture of their profession, its six categories or "building blocks of a health system" (vi) failed to capture the social challenges around shared beliefs, values, and norms that some physicians voiced as system flaws in their stories. We, therefore, expanded our interpretation to include the professional culture of medicine as constituting a 'system' (Parsons 1951).

Using techniques of content and narrative analysis (Bleakley 2005; Riessman 2008; Clandinin 2016), we analyzed the types of system flaws and physicians' orientation to the flawed system - that is, whether physicians positioned themselves as insiders or outsiders to the system and whether they expressed agency to evoke change or claimed complicity in the system flaw they wrote about. Narrative inquiry is "an approach to the study of human lives conceived as a way of honoring lived experience as a source of important knowledge and understanding" (Clandinin 2016, 17). Here, each individual story matters: "What distinguishes narrative inquirers is their understanding that understanding the complexity of the individual, local, and particular provides a surer basis for our relationships and interactions with other humans" (Pinnegar and Daynes 2007, 30). Narrative ways of knowingemphasize interpretation of human experience (Josselson and Lieblich 1995, ix-xii) and thus represent a departure from a scientific paradigm, which privileges objectivity, quantitative data, and generalizability and validity of results (Pinnegar and Daynes 2007, 7-28). Our disciplines and experiences influenced our design and analytical choices, which reflect our backgrounds in qualitative research and narrative analysis. The team comprised three academic researchers (TM, RP, LL) with backgrounds in communication, sociology, and rhetoric, respectively, and an academic clinician $(\mathrm{CW})$. Two team members are medical education leaders (LL, CW). Using narrative inquiry techniques enabled us, in this study, to consider not only what was happening in the narratives but also how the story was told. We therefore considered both the content (what the words themselves communicated) and the form (including storytelling categories such as orientation and agency). Such an interpretive narrative analysis has the potential to tell us more about the research question than the content alone (Charon 2012; Moniz et al. 2019; Riessman 2008, 77).

As a method, narrative inquiry offers a way of "thinking about stories" (Bleakley 2005, 535) - a method of "inductively producing categories from the raw narrative data," often a "framework or typology that can be applied back to narratives for explanation or illumination" (537). Thus, two authors (TM, RP) developed the initial coding scheme through an iterative process of independently reading and open-coding and then discussing a sample of narratives. Another author $(\mathrm{CW})$ reviewed several narratives to compare and discuss patterns. The two authors (TM, RP) then independently read and coded all narratives, meeting regularly to discuss coding decisions and refine the coding scheme to reflect new insights from the data. Narratives coded earlier in the process were revisited and re-coded at the end, as needed. We held monthly team meetings to resolve discrepancies and to discuss narratives that challenged our assumptions (e.g., of what constituted 'agency'). We then explored the relationships between and across the codes to identify patterns, focusing on the relationship between the type of flaw and the physicians' orientation to the flawed system. 


\section{Results}

\section{What physicians identified as flawed about the 'system'}

Given that physicians routinely write laments about flaws with the healthcare system (Moniz, Lingard, and Watling 2017, 124-5), we anticipated that they would largely point to factors and forces outside the profession as flawed. Instead, we found that physicians most often looked inward-at the culture of medicine itself-when writing about the prevailing challenges compromising their ability to be the kind of professionals they want to be. We identified seven recurring and, at times, overlapping system flaws. Five of these flaws related to the culture of medicine: the failures of communication, the erosive impact of the hidden curriculum, inadequate health advocacy, the frenzied pace of work, and the experience of stigma. Together, flaws related to medical culture accounted for two-thirds of flaws identified. The two remaining flaws addressed (nearly evenly) restrictive institutional practices as well as limited and disparate healthcare resources. Below, we elaborate these themes, beginning with those connected with medicine's professional culture.

\section{Failures of communication}

Issues of communication failure dominated, comprising one-third of total narratives about medical culture. Physicians wrote about how the language entrenched in medicine can erode the physician-patient relationship; how small acts of empathetic verbal and nonverbal communication are undervalued and undertaught; how breaking bad news is often focused on the illness, not the person; and how a lack of communication between peers impedes collaboration. For example, a physician recalled a moment of communication failure-peer-to-peer, physician-patient, and physician-family_during her training as a pediatric oncology fellow: "When she relapsed again, I sat quietly in the family meeting and listened as the bone marrow transplant specialist told her in stark language that she was going to die. I felt steamrolled by other clinicians, some of whom seemed impatient to fix $\mathrm{K}$ on a predictable end-of-life care trajectory. The statistics were grim, but I believed that $\mathrm{K}$ and her family needed time, first to absorb the news of the relapse and then to reflect on their hopes, goals, and priorities" (Caruso Brown 2017, 2487). Moreover, this physicianwriter was, as she put it, "their doctor" (2487) - the one the family built a rapport with and trusted. In this narrative, she therefore grappled not only with her colleagues' lack of compassion in communicating but also with her own feelings of being "ashamed of having silently allowed the meeting to proceed with such disregard for a patient and a family" (2487). This collection of narratives foregrounding communication failures emphasized the central role that communication plays in shaping the doctor-patient relationship and, in particular, building trust, and called out the impact of poor communication on patient outcomes, quality of care and physician wellness.

\section{The erosive impact of the hidden curriculum}

Physicians and medical learners also wrote about the ways that the hidden curriculum"a set of influences that function at the level of organizational structure and culture" (Hafferty 1998, 404)_erodes patient-centred care and their own wellness. 
They wrote about the disconnect between the teaching and enactment of empathythat repeating concepts in the classroom doesn't guarantee their practice at the bedside, especially when the culture of medical school encourages detachment in the face of suffering. One medical learner shared this insight stemming from his experiences as a patient before starting medical school and his subsequent reflections following his first year of medical training: "Perhaps the practice of medicine suffers from a tendency to overanalyze, opting to critically evaluate instead of truly understand. As students, we are told that empathy and compassion are traits for us to learn, that they are to be practiced and implemented. The problem is that the patient experience of these concepts is far more subtle than an academic discussion can relate. Countless emotions of the caregiver are intertwined with empathy and compassion, and the incongruence in our system is in how we display those emotions to our patients" (Markwalter 2015, 900). Training for empathy requires more than "a purely academic understanding of these concepts" (899), and physician-writers emphasized that the best lessons about the "human side of medicine' cannot be taught in the classroom but, rather, are learned in practice and through interacting with patients.

In this group of narratives about the erosive impact of the hidden curriculum, physicians also reflected on how the structure and culture of medical school is challenging for trainees who struggle silently with its pressures. For example, one physician reflected on the suicide of a fourth-year medical student at his institution: "Every time students achieve what looks to the rest of us like a successful milestone-getting into a great college, the medical school of their choice, a residency in a competitive clinical specialty-it is to some of them the opening of another door to a haunted house, behind which lie demons, suffocating uncertainty, and unimaginable challenges. Students bravely meet these challenges head-on while we continue to blindly ratchet up our expectations.... [W] never let up on them-and it's killing them" (Muller 2017a, 1102). This physician, like others whose narratives we analyzed, pointed to "a culture of performance and achievement" as among the "root causes of this national epidemic of burnout, depression, and suicide" among medical students (1102). This collection of narratives called out the 'sink or swim' mentality that pervades the culture of medical education, with high standards of performance, little room to make mistakes, and a lack of attention to student wellbeing.

\section{Inadequate health advocacy}

Physicians also reflected on how inadequate health advocacy on their part, at both individual and population levels, perpetuates practices, policies and/or systems that compromise patient-centred care and that disadvantage the health(care) of vulnerable and marginalized populations.

Their narratives emphasized how a lack of advocacy for individual patients may lead to poor diagnostic and prescribing practices — and vice versa - notably with vulnerable populations, minors and those with mental illness. For instance, physicians wrote about how the uniform application of treatment guidelines - rather than attention to individual needs and circumstances-may harm some patients. One narrative focused on the default recommendation or practice of ceasing mental health medications in pregnant women. The physician wrote: "We need to step back and view medication exposure in pregnancy as only one of the many potential risks faced by seriously mentally ill women when they are pregnant. We have a long way to go to provide the care and help these women and their unborn babies need and deserve" (Dossett, Wusirika, and Burt 2017, 30). Physicians understood the need 
to advocate in the individual patient's best interests but also recognized the associated challenges when working within or with systems like hospitals or insurance companies. One physician noted: "We need a system that rewards the physician who understands the limitations of guidelines" (Sarosi 2015, 563).

Physicians' narratives also emphasized that a lack of advocacy at the population level reinforces health disparities. In one narrative, a physician confronted his own political inaction in advocating for underserved patients: "Should my desire for apolitical professionalism outweigh the needs of black patients who die as a result of collective inaction? Should I allow policy leaders to perpetuate racial disparities in access to care, while Black Lives Matter protesters are shot in the street? And why should I be so reluctant to outwardly promote an agenda of health care expansion, simply because it may be interpreted as favoring one political party over another? My typical response to these questions is, unfortunately, silence" (O'Connor 2016, 2170). When a patient encounter placed racial disparities at the forefront of this physician's practice, he was left questioning the limits and responsibilities of his role. A unique aspect of this physician's writing is the way he appears to shoulder blame so personally, directing it inward and calling out his own privileging of apoliticism over advocacy, rather than pointing to the broader culture of medicine.

\section{The frenzied pace of work}

In their narratives, physicians considered how medicine's frenzied pace constrains their ability to interact meaningfully with patients (despite their desire to do so), limits their opportunities for a social or family life, and contributes to burnout. Physicians reflected on the demands and sacrifices of a career in medicine and, as one physician described it, the "fine and costly line" that they walk between love of family and dedication to the job: "Will they one day understand the reason for all those missed moments, or will they resent me for it?" (Waxman 2017, 752). Furthermore, physicians' patient load and number of tasks on any given day are overwhelming, particularly for trainees, and the time available to complete these tasks conflicts with the time needed to ask deeper questions of patients that lead to better diagnoses and/or treatment and that build rapport and trust. When 'task' trumps 'patient,' as physicians lamented it often does, then patient-centred care dwindles. A physician described such a moment: "This would have been the time to ask him the questions that it hadn't been possible to ask when he first arrived, to ask him what his life was like before he was in the hospital. Where did he sleep at night? What demons drove him to drink so much? Were there any demons that drove him to drink? Did he want to quit? But I didn't do that. Instead, I rushed in, checked his vital signs, listened quickly to his lungs, and asked briefly whether he needed anything. I remembered my tasks, checked my boxes, and kept moving" (Gregg 2017, 1442).

This group of narratives focused on the day-to-day fatigue that physicians experience on the job, and the ways that the volume of work and the long hours contributed to burnout, dissatisfaction and general despair among physicians. One physician reflected on a rotation during his internship when "days were a frantic blur, a whirlwind of activity, endless scut lists that I never seemed to get to the bottom of" (Muller 2017b, 907). About the impact of this period in his training, he wrote: "I survived because the rotation eventually played itself out. I had held my breath long enough to make it to the end of that long, dark tunnel. That was rock bottom for me: hopeless and helpless with something that I only later recognized as the desire to die in order to escape from what seemed at the time to be a fate worse than death" (907). 


\section{The experience of stigma}

The final flaw related to the culture of medicine was stigma. Physicians wrote about how stereotypes and biases about race, addiction, and disability pervade medical culture and affect both physicians and patients. The stigma - and silence - around mental health and addiction within the profession contributes to burnout and self-harm or suicide. To illustrate, one physician with a history of depression, suicidal ideation, and alcoholism commented that he "often felt branded, tarnished, and broken in a system that still embroiders a scarlet letter on the chest of anyone with a mental health condition" (Hill 2017, 1103). He shared this lesson from his own "recovery journey" (1103): "It's ironic that mental health conditions are so stigmatized in the medical profession, given that physicians long fought to categorize them as medical diagnoses. Why do medical institutions tolerate the fact that more than half their personnel have signs or symptoms of burnout? When mental health conditions come too close to us, we tend to look away-or to look with pity, exclusion, or shame. We may brand physicians who've had mental health conditions, while fostering environments that impede their ability to become and remain well" (1104). Implicit biases further contribute to health disparities and shape the treatment pathways for patients with mental illness, addiction or disability, often manifesting in substandard treatment or serious harm. In reference to disability, one physician wrote: "Jean faced attitudinal barriers: clinicians' attitudes led them to assume that Jean couldn't handle chemotherapy, which they did not confirm before making treatment decisions" (Rosland 2015, 2229). Thus, implicit biases as well as stereotypes rooted in faulty assumptions about race, addiction and disability pervade medical culture and affect both the practice of medicine and relations between peers in subtle and overt ways.

\section{Restrictive institutional practices}

Physicians wrote about how institutional practices, such as staffing, service delivery or discharge guidelines, are inflexible and not patient centred. Narratives in this grouping drew attention to the unintended effects of institutional practices and policies on the quality of care that patients receive as well as on physicians' wellbeing. About weekend staffing practices, one physician-turned-family caregiver noted that "[f]rom the physician's perspective, weekends in the hospital are all about coverage" (Klass 2015, 402). She went on to share this insight about the "comfortless landscape" she experienced as a caregiver on weekends: "But when your parent or child is sick and scared, it can be shocking to hear, over and over, about the ways that weekends are slower and things don't get done. The sick person's calendar is marked out in difficult days and sleepless nights, or in agonizing hours, but it takes no notice of days of the week, makes no distinction between time and overtime" (403). Such a lack of patient-centredness in institutional practices may reflect what one physician described as a shift over the last decade where "our collective attention has turned away from relational aspects of medical care and been replaced by a greater emphasis on transactional aspects" (Sinsky 2017, 600). In this view, the values of "relationship, continuity, broad competence, and satisfaction" give way to a system of patient care that is "increasingly fragmented and shift-oriented" (600). One physician wrote: "Physicians have always served patients, but we've also started to serve the systems around us-hospital systems, information technology systems, and, especially, the great amorphous 'health care system.' The systems stake their own claim to taking care of patients" (Clark 2016, 872). 
Institutional practices that privilege efficiency or finances over humanistic care erode the physician-patient relationship and lead to feelings of dissatisfaction among physicians who experience a disconnect between their professional values and institutional priorities. Writing about the practice of transmitting test results electronically to patients, one physician noted: "As we allow ourselves to become more distant from our patients - acting merely as technicians or proceduralists - we abdicate our role as humanitarian physicians. And as the chasm between physician and patient widens, we ourselves become more disengaged, frustrated, and disappointed with our careers" (Friedman 2016, 2276). Here, the physician's choice of words- "as we allow ourselves"-positioned him at the centre of the flawed system, rather than lamenting a system that he was an outsider to.

\section{Limited and disparate healthcare resources}

Physicians, in their narratives, also explored how resource limitations and disparities impact the quality of care, especially for marginalized populations. They wrote about how inadequate access to health care resources-such as specialist and general practitioners, medications, screening, and other lifesaving technologies-persists in many communities. While underdeveloped countries have the fewest resources to distribute, resource limitations and disparities persist in the developed world too. Moreover, physicians wrote about how specific populations are more greatly impacted by resource limitations and disparities than others, either because of geography (i.e., rural or northern communities or the Global South), specialized needs (i.e., those with mental illness or disability or older adults), or both. As an example, an oncologist reflected on the impact of a lack of mental health resources in rural communities in the United States: "Her death left me with feelings of profound failure. What good were targeted therapies when her coexisting mental illness prevented her from taking them? And I had been unable to palliate her suffering until her very last days of life.... I could not provide [effective] care because I lacked the tools and training to overcome the barrier of mental illness" (Lycette 2016, 2221). This quote exemplifies what many narratives communicated - that resource limitations and disparities contribute to distress and burnout for physicians who struggle to provide minimal standards of care in resource-strapped settings. Physicians wrote about times when they found themselves in stressful situations and settings where their ability to provide quality medical care and to cultivate meaningful doctor-patient relationships was limited. In such times, the focus was on basic health care, not building relationships, not patient-centredness, and not humanistic care.

\section{How physicians perceived their own agency to change the flawed 'system'}

Most physicians positioned themselves as insiders to the flawed system they wrote about (e.g., as members of a professional culture that stigmatizes addiction among its own) (Hill 2017, 1103-4) rather than as outsiders to it (e.g., as supporting a patient in navigating a 'flawed' health insurance system) (Campbell 2017, 1953-4). In a majority of narratives, physicians expressed agency - individual foremost and then collective - to bring about change. This sense of agency was most prominent when writing about flaws related to the professional culture of medicine, notably communication failures, the hidden curriculum, and stigma. Physicians often pointed to the ways the profession is not living up to its ideals and took the position that they could — and should — do something about it, starting with individual acts of resistance or change. In one narrative, a first-year resident described her 
decision to linger at the bedside of a patient with an impending cancer diagnosis rather than be on time for morning report: "Over the past 3 hours, you've placed more than 50 orders, answered 17 pages, listened to 14 hearts and 28 lungs, talked to countless patients, nurses, residents, and social workers, but you realize that this is the only real doctoring you'll do today. These are the 60 seconds that will matter" (Singh 2017, 2317). Amid the frenzied pace of the clinic, this "overworked, self-doubting, burned out" resident made a choice to prioritize the patient (2317).

Conversely, physicians were most apt to position themselves as outsiders to the flawed system when writing about resource limitations and disparities. Physicians were also most apt to express a complicity or powerlessness when writing about restrictive institutional practices that prioritize economics and efficiency over patient-centred care as well as resource limitations and disparities that may call for broader administrative or sociopolitical change. For example, one "fly-in physician" (Jegen 2017, E782) serving remote northern Canada wrote this about a rushed patient encounter:

In my rush and exasperation to get to my flight, I explained that I still had booked patients to see and a flight at $5 \mathrm{pm}$, and simply could not see her for this today. I gave Dora the option of seeing the female nurse or to be booked with the next doctor in one month. Dora kept crying and then said, 'But you are the doctor and you're right here.' This stopped me in my tracks. I do not remember the last time that I felt that .... feeling that I was so deeply in the wrong. I am the doctor. I was right there.

Here, the physician's sense of shame reflects the struggle between a culturally-influenced sense of personal responsibility to 'show up' for the patient and broader system issues that were largely outside the physician's control.

\section{Discussion}

Physicians' stories offer a reflective critique of the profession. In our analysis, what physicians found most flawed about the 'system' was the culture of medicine itself. Physicians looked inward to reflect critically on how they conduct themselves, what values they embrace and fail to embrace, and how medical culture compromises patient-centred care and perpetuates bias and burnout in the profession. While physicians painted a dark picture of the effects of flawed systems on their own wellness, they also expressed agency and responsibility to live up to ideals that are threatened by these system challenges. Thus, physicians feel simultaneously beaten down by these system flaws and also burdened by a sense of responsibility to address them.

In the stories analyzed, narrative functions as a vehicle for critical reflection on the self and on the practice of medicine. Writing has therapeutic value for physicians (Peterkin and Prettyman 2009; Roscoe 2009, 68). Collectively, physicians' writings become "therapeutic acts of witness" (Roscoe 2009, 67). Physicians bear witness to many intense moments of human life-birth and death, illness and healing, suffering and joy-not only throughout their careers but potentially on any given day. Writing becomes an outlet for processing such moments and the thoughts, feelings, and questions that accompany them. Roscoe notes: "People are particularly drawn to create stories about life events that disrupt their life narratives" $(2009,68)$. We see this pattern in physicians' tendency to write stories about flaws with the systems in which they work. Writing about these intense or disruptive 
moments in medical practice "can allow them to be understood and processed in ways that can preserve the well-being of professional caregivers" (68). Moreover, writing about medical practice — the joys and the flaws—can be "deeply enlivening" (Scannell 2002, 780). As Scannell explains: "Giving language to what we witness lifts into personal and, sometimes, public consciousness the otherwise unarticulated existential dimensions of experience that permeate our work" (780-1).

We saw tension in the stories between elements outside the physician's control and those within it. Physicians expressed a desire to live up to the aspirational identity of the profession in the face of system pressures that render that identity increasingly infeasible in day-to-day medical practice. This tension is a source of existential distress for physicians. Physicians are not only frustrated by a flawed system and the constraints it places on quality of care, but they can also feel a deep sense of distress when the compromises that emerge from system flaws move them away from the values that define their identities as doctors. The 2020 COVID-19 pandemic has brought this simmering distress into sharp relief, revealing system flaws and illuminating the angst of doctors who feel powerless to practice in the way they were trained.

One physician likened the state of the medical profession to the failure of Boston's John Hancock Tower in 1973 (Babbott 2016). Like the glass-paned skyscraper whose faulty engineering caused large panels of glass to crack and fall with high winds, so too does the medical profession have "stressors" that expose its precarious structure and inevitably create "microfractures" that cause physicians to "struggle and fall," with far-reaching impacts (597). And like the "glass watchers" hired to look for colour changes in the glass panesthe "telltale sign of danger"- - so, too, does the medical profession need such "intentional watching, specific direction and dedication of resources applied to the investigation and mitigation of stress" (597). As this physician wrote: "We, too, can learn the lessons, from how to observe and reengineer to how we can redesign the workplace and restructure our profession" (598). Physicians' published stories serve as reminders to peers and to the profession that flaws with the 'system' must not make them lose sight of what being a doctor is really about.

At times, their published stories also offered ways forward-a path toward self-empowerment and change. These included individual acts, such as when to leverage technology and when to set it aside to maximize communication with patients and peers (Czernik and Lin 2016; Drazen 2016), or recognizing the potential of role modelling and mentoring trainees as a critical part of changing the culture of medicine in the direction of patient-centred care and physician wellness. One physician wrote about the need to integrate "emotional management" into programming designed to increase mindfulness and prevent burnout of early career physicians: "Young physicians, like myself, need to learn how to process and manage their emotions. They need to identify the emotions that improve patient interactions and promote healing and be mindful of emotions that may detract from these goals. Senior physicians should be responsible for creating safe spaces for students and residents to freely discuss emotionally charged patient scenarios and provide emotional support and guidance" (Corey 2017, 798). Such an effort aims to mitigate burnout by developing resiliency in individual physicians, a common strategy for coping with stressors of medical practice (Collier 2018; West et al. 2016). However, change must occur at the systems level, too (Collier 2018; West et al. 2016), and physicians' stories also offered ways forward that included collective action at institutional, political and/or societal levels. For instance, to "build and maintain a culture of shared purpose" across an institution-one of "empathetic, coordinated care"-one physician emphasized the value of sharing stories about both successes and failures: "As systems, we have to recognize and 
acknowledge our mistakes, our shortcomings, just as individual physicians do. We need to reflect on times when our care has deviated from what we intended - when we haven't been who we hoped to be. We have to be transparent and allow the failure to reshape us, to help us reset our intention and mold our future selves" (Awdish 2017, 8). The very act of writing and publishing a narrative may be a way forward in itself. Watling, Ajjawi and Bearman contend that culture change can, at times, be effected by articulating new stories that slowly begin to shift how a culture defines itself: “... wholesale culture change cannot rest with a single individual. Changing cultural worlds necessarily involves community engagement: acts of resistance that are shared at grassroots levels" (2020, 293). Writing and sharing stories can serve as an "act of resistance" that may, in turn, stimulate the community engagement required to shift culture (292).

Within the field of medical humanities, our analysis of physicians' published stories deepens understanding of how physicians are using narrative to navigate and share challenges experienced in practice, and it offers insight into the problem of burnout-what individual physicians identify as flawed and frustrating about the system; the harmful effects of these challenges, notably flaws related to medical culture, on physician wellbeing; and how physicians understand their own agency and responsibility to advocate for systems-level change. This research also has implications for medical education. Currently, medical education strives to train 'systems-literate' doctors who can recognize challenges in the system and enact change. What this educational mission tends to miss is that many of the challenges are cultural as much as organizational, and addressing cultural challenges may require different skills and knowledge. For instance, one medical student reflected on the duty of education to explore the role of medical culture in perpetuating racialized health disparities. She wrote: "I give credit to my medical school for teaching me to be critical of the culture of medicine, apply interdisciplinary perspectives to clinical quandaries, and reflect on my experiences.... I believe that if we refuse to deeply examine and challenge how racism and implicit bias affect our clinical practice, we will continue to contribute to health inequalities in a way that will remain unaddressed in our curriculum and unchallenged by future generations of physicians" (Brooks 2015, 1909-10). Addressing cultural challenges may also require attention to role modelling and mentorship in medical education. For instance, the narratives focused on the erosive impact of the hidden curriculum emphasized the need for physician-educators to guide trainees in navigating difficult emotional experiences in medical training. As one physician reflected: "[W]hen a medical trainee has undergone a difficult experience and tells you that he or she is okay, don't believe it. Ask more, come back later, empathize, offer your own experiences" (Misch 2016, 888).

We have identified sources of tension and distress for physicians. Future research may explore how physicians work to manage and resolve these tensions, particularly in the aftermath of the COVID-19 pandemic when the profession will be called on to rebuild and refortify the healthcare system, and how they succeed or fail in exercising agency within the healthcare system to effect change.

This study has limitations. While author instructions in these journals are broad, we recognize that editorial decision-making may have skewed stories in a particular direction; thus, stories that looked inward at medical culture were not necessarily more frequently submitted but potentially more frequently viewed as compelling by editors. Moreover, physicians who chose to express their views in writing may not be representative of their broader community. Our use of physicians' written narratives is further subject to the inherent limitations of narrative itself, including questions about truth and assumptions about its universality and innate character. Furthermore, while the narratives describe experiences in 
different countries with different health systems, we analyzed them collectively rather than compare perspectives from Canada $(n=9)$, the United States $(n=74)$, abroad $(n=3)$ or otherwise (i.e. anonymous, $n=1$ ). We lacked a robust set of narratives outside the United States to yield reliable comparative inferences about specific health systems. That virtually all included narratives represented North American perspectives may further limit the salience of our findings for those working in other systems.

\section{Conclusion}

Everyone loves to critique the healthcare system. This is not new. What is new is that physician narratives tend to focus more on system flaws within medical culture. This study points to the culture of medicine (and specific aspects of that culture) as creating a situation of tension for physicians, because while they are challenged by these system flaws, physicians nevertheless feel a sense of responsibility or agency to practice in ways that do not just succumb to them. These voices from the front lines are worth listening to because they give us insight into how, in the face of enormous system pressures, physicians are trying to maintain resilience and live up to the ideals of the profession.

Supplementary Information The online version contains supplementary material available at https://doi. org/10.1007/s10912-021-09690-6.

\section{References}

Abbott, Porter H. 2008. The Cambridge Introduction to Narrative. 2nd ed. Cambridge: Cambridge University Press.

Awdish, Rana L.A. 2017. "A View from the Edge - Creating a Culture of Caring." New England Journal of Medicine 376 (1): 7-9.

Babbott, Stewart F. 2016. "The Glass Watchers.” Annals of Internal Medicine 165:597-598. https://doi.org/ 10.1056/NEJMp1614078.

Barthes, Roland. 1977. "Introduction to the Structural Analysis of Narratives." In Image, Music, Text, translated by Stephen Health, 79-124. London: Fontana Press.

Bleakley, Alan. 2005. "Stories as Data, Data as Stories: Making Sense of Narrative Inquiry in Clinical Education." Medical Education 39 (5): 534-540. https://doi.org/10.1111/j.1365-2929.2005.02126.x.

Brooks, Katherine C. 2015. "A Silent Curriculum.” Journal of the American Medical Association 313 (19): 1909-1910.

Bruner, Jerome. 1986. Actual Minds, Possible Worlds. Cambridge: Harvard University Press.

Campbell, Bruce H. 2017. "Determination." Journal of the American Medical Association 317 (19): 1953-1954.

Campbell, Darrell A., Seema S. Sonnad, Frederic E. Eckhauser, Kyle K. Campbell, and Lazar J. Greenfield. 2001. "Burnout among American Surgeons." Surgery 130 (4): 696-705. https://doi.org/10.1067/msy. 2001.116676.

Canadian Medical Association. 2018a. "One in Four Canadian Physicians Report Burnout.” October 10. Accessed 1 May 2020. https://www.cma.ca/one-four-canadian-physicians-report-burnout.

Canadian Medical Association. 2018b. "CMA National Physician Health Survey." Canadian Medical Association. Accessed 1 May 2020. https://www.cma.ca/sites/default/files/2018-11/nph-survey-e.pdf.

Caruso Brown, Amy E. 2017. "Porous Boundaries." Journal of the American Medical Association 317 (24): 2487-2488.

Charon, Rita. 2005. "Narrative Medicine: Attention, Representation, Affiliation.” Narrative 13 (3): 261-270.

-----. 2006. Narrative Medicine: Honoring the Stories of Illness. Oxford: Oxford University Press.

-----. 2012. "At the Membranes of Care: Stories in Narrative Medicine." Academic Medicine 87 (3): $342-$ 347. https://doi.org/10.1097/ACM.0b013e3182446fbb. 
Charon, Rita, and Nellie Hermann. 2012. "Commentary: A Sense of Story, Or Why Teach Reflective Writing?" Academic Medicine 87 (1): 5-7. https://doi.org/10.1097/ACM.0b013e31823a59c7.

Charon, Rita, Sayantai DasGupta, Nellie Hermann, Craig Irvine, Eric R. Marcus, Edgar Rivera Colón, Danielle Spencer, and Maura Spiegel. 2017. The Principles and Practices of Narrative Medicine. New York: Oxford University Press.

Clandinin, D. Jean. 2016. Engaging in Narrative Inquiry. London: Routledge.

Clark, Bennett W. 2016. “A Place to Stay.” Journal of the American Medical Association 315 (9): 871-2.

Collier, Roger. 2018. "Addressing Physician Burnout at the Systems Level." Canadian Medical Association Journal News. 12 February. Accessed 1 May 2020. https://www.cmaj.ca/content/190/6/E174.

Corey, Elizabeth. 2017. “Delivering Emotions.” Journal of the American Medical Association 318 (9): $797-798$.

Coulehan, J. 2007. "Written Role Models in Professionalism Education.” Journal of Medical Ethics; Medical Humanities 33 (2): 106-109.

Czernik, Zuzanna, and C.T. Lin. 2016. "Time at the Bedside (Computing)." Journal of the American Medical Association 315 (22): 2399-2400.

Dossett, Emily C., Lavanya Wusirika, and Vivien Burt. 2017. "No Perfect Choice.” Journal of the American Medical Association 318 (1): 29-30.

Drazen, Jeffrey M. 2016. "Hearing Without Listening.” New England Journal of Medicine 375 (15): 1412-3. https://doi.org/10.1056/NEJMp1612158.

Dyrbye, Liselotte N., and Tait D. Shanafelt. 2011. "Physician Burnout: A Potential Threat to Successful Health Care Reform.” Journal of the American Medical Association 305 (19): 2009-10. https://doi.org/10.1001/ jama.2011.652.

Dyrbye, Liselotte N., Tait D. Shanafelt, Charles M. Balch, Daniel Satele, Jeff Sloan, Julie Freischlag. 2011. "Relationship between Work-Home Conflicts and Burnout among American Surgeons: A Comparison by Sex." Archives of Surgery 146 (2): 211-217.

Frank, Arthur W. 2013. The Wounded Storyteller. 2nd ed. Chicago: The University of Chicago Press.

Friedman, Ellen M. 2016. "You've Got Mail." Journal of the American Medical Association 315 (21): 2275-2276.

Gregg, Jessica. 2017. “Better.” Journal of the American Medical Association 318 (15): 1441-1442.

Hafferty, Frank W. 1998. "Beyond Curriculum Reform: Confronting Medicine's Hidden Curriculum." Academic Medicine 73 (4): 403-407.

Hill, Adam B. 2017. "Breaking the Stigma - A Physician's Perspective on Self-Care and Recovery." New England Journal of Medicine 376 (12): 1103-1104. https://doi.org/10.1056/NEJMp1615974.

Hunter, Kathryn Montgomery. 1993. Doctors' Stories: The Narrative Structure of Medical Knowledge. Princeton: Princeton University Press.

Jegen, Dominika A. 2017. "A Reflection on Practicing Medicine 'Up North."” Canadian Medical Association Journal 189 (22): E781-783. https://doi.org/10.1503/cmaj.161100.

Jennings, M.L., and Stuart J. Slavin. 2015. "Resident Wellness Matters: Optimizing Resident Education and Wellness through the Learning Environment." Academic Medicine 90 (9): 1246-1250.

Johna, Samir, Brandon Woodward, and Sunal Patel. 2014. "What Can We Learn from Narratives in Medical Education?” Permanente Journal 18 (2): 92-94. https://doi.org/10.7812/TPP/13-166.

Josselson, Ruthellen, and Amia Lieblich, eds. 1995. Introduction. In Interpreting Experience: The Narrative Study of Lives, edited by Ruthellen Josselson and Amia Lieblich, ix-xii. Thousand Oaks: Sage.

Klass, Perri. 2015. "Death Takes a Weekend." New England Journal of Medicine 372 (5): 402-405. https://doi. org/10.1056/NEJMp1413363.

Lycette, Jennifer. 2016. "Neglected - Cancer Care and Mental Health in Rural America. New England Journal of Medicine 375 (23): 2220-2221. https://doi.org/10.1056/NEJMp1612129.

Mann, Karen, Jill Gordon, and Anna Macleod. 2009. "Reflection and Reflective Practice in Health Professions Education: A Systematic Review." Advances in Health Sciences Education 14 (4): 595-621. https://doi. org/10.1007/s10459-007-9090-2.

Markwalter, Daniel Webb. 2015. "In the Hands of Another.” Journal of the American Medical Association 313 (9): 899-900.

Martin, Viv. 2007. "Dialogue in the Narrative Process." Journal of Medical Ethics; Medical Humanities 33 (1): 49-54. https://doi.org/10.1136/jmh.2007.000246.

Maslach, Christina, and Michael P. Leiter. 2016. "Understanding the Burnout Experience: Recent Research and Its Implications for Psychiatry.” World Psychiatry 15 (2): 103-111.

McKechnie, Claire Charlotte. 2014. "Anxieties of Communication: The Limits of Narrative in the Medical Humanities." Medical Humanities 40:119-124. https://doi.org/10.1136/medhum-2013-010466.

Misch, Donald A. 2016. "A Vulnerable Moment." Annals of Internal Medicine 165:887-8. https://doi.org/10. 7326/M16-0438.

Moniz, Tracy, Lorelei Lingard, and Chris Watling. 2017. "Stories Doctors Tell." Journal of the American Medical Association 318 (2): 124-125. https://doi.org/10.1001/jama.2017.5518. 
Moniz, Tracy, John Costella, Maryam Golafshani, Chris Watling, and Lorelei Lingard. 2019. "Bringing Narratives from Physicians, Patients and Caregivers Together: A Scoping Review of Published Research." Medical Humanities: 1-11.https://doi.org/10.1136/medhum-2017-011424.

Muller, David. 2017a. "Kathryn.” New England Journal of Medicine 376 (12):1101-1105. https://doi.org/10. 1056/NEJMp1615141.

-----. 2017b. “Rock Bottom.” Annals of Internal Medicine 166:907-908.https://doi.org/10.7326/M16-2177.

O'Connor, Jeremy. 2016. "Black Lives.” Journal of the American Medical Association 315 (20): 2169-2170.

Parsons, Talcott. 1951. The Social System. New York: The Free Press and Collier Macmillan.

Peterkin, A.D., and A.A. Prettyman. 2009. "Finding a Voice: Revisiting the History of Therapeutic Writing. Journal of Medical Ethics; Medical Humanities 35:80-88. https://doi.org/10.1136/jmh.2009.001636.

Pinnegar, Stefinee, and J. Gary Daynes. 2007. "Locating Narrative Inquiry Historically: Thematics in the Turn to Narrative." In Handbook of Narrative Inquiry: Mapping a Methodology, edited by D. Jean Clandinin, 3-34. Thousand Oaks: SAGE Publications.

Riessman, Catherine Kohler. 2008. Narrative Methods for the Human Sciences. Los Angeles: SAGE.

Roscoe, Lori A. 2009. "Therapeutic Acts of Witness: Why Writing Poetry and Prose Has Never Been Just for Physicians.” Journal of Medical Ethics; Medical Humanities 35 (2): 67-69.

Rosland, Ann-Marie. 2015. “Assuming the Worst.” Journal of the American Medical Association 313 (22): 2229-2230.

Sarosi, George A. 2015. "The Tyranny of Guidelines." New England Journal of Medicine 163: 562-563. https:// doi.org/10.7326/M15-1202.

Scannell, Kate. 2002. "Writing for Our Lives: Physician Narratives and Medical Practice." Annals of Internal Medicine 137 (9): 779-781.

Shanafelt, Tait D. 2009. "Enhancing Meaning in Work: A Prescription for Preventing Physician Burnout and Promoting Patient-Centered Care.” Journal of the American Medical Association 302 (12):1338-1340.

Shanafelt, Tait D., Katharine A. Bradley, Joyce E. Wipf, and Anthony L. Back. 2002. "Burnout and Self-Reported Patient Care in an Internal Medicine Residency Program.” Annals of Internal Medicine 136 (5): 358-367.

Shanafelt, Tait D., Omar Hasan, Lotte N. Dyrbye, Christine Sinsky, Daniel Satele, Jeff Sloan, and Colin P. West. 2015. "Changes in Burnout and Satisfaction with Work-Life Balance in Physicians and the General US Working Population Between 2011 and 2014." Mayo Clinic Proceedings 91 (12): 1600-1613. https://doi. org/10.1016/j.mayocp.2015.08.023.

Shanafelt, Tait D., and John H. Noseworthy. 2017. "Executive Leadership and Physician Well-Being: Nine Organizational Strategies to Promote Engagement and Reduce Burnout.” Mayo Clinic Proceedings 92 (1): 129-146. https://doi.org/10.1016/j.mayocp.2016.10.004.

Shanafelt, Tait D., Michelle Mungo, Jaime Schmitgen, Kristin A. Storz, David Reeves, Sharonne N. Hayes, Jeff A. Sloan, Stephen J. Swensen, and Steven J. Buskirk. 2016. "Longitudinal Study Evaluating the Association between Physician Burnout and Changes in Professional Work Effort." Mayo Clin Proceedings 91 (4): 422-431. https://doi.org/10.1016/j.mayocp.2016.02.001.

Shanafelt, Tait D, Jeff A. Sloan, and Thomas M. Habermann. 2003. "The Well-Being of Physicians." American Journal of Medicine 114:513-517. https://doi.org/10.1016/S0002-9343(03)00117-7.

Singh, Sonia. 2017. "Morning Report.” New England Journal of Medicine 376 (24): 2316-2317. https://doi.org/ 10.1056/NEJMp1701939.

Sinsky, Christine A. 2017. “On Continuity.” Annals of Internal Medicine 167:600. https://doi.org/10.7326/M17-0303.

Watling, Christopher J., Rola Ajjawi, and Margaret Bearman. 2020. "Approaching Culture in Medical Education: Three Perspectives." Medical Education 54:289-295.

Waxman, Sergio. 2017. “2:32 a.m.” Annals of Internal Medicine 167:752.

West, Colin P., Liselotte N. Dyrbye, Patricia J. Erwin, and Tait D. Shanafelt. 2016. "Interventions to Prevent and Reduce Physician Burnout: A Systematic Review and Meta-Analysis.” Lancet 388:2272-2281. https://doi. org/10.1016/S0140-6736(16)31279-X.

Woods, Angela. 2011. "The Limits of Narrative: Provocations for the Medical Humanities." Medical Humanities 37:73-78. https://doi.org/10.1136/medhum-2011-010045.

World Health Organization. 2007. Everybody's Business: Strengthening Health Systems to Improve Health Outcomes: WHO's Framework for Action. Geneva: World Health Organization. Accessed 1 May 2019. https:// www.who.int/healthsystems/strategy/everybodys_business.pdf.

Younie, L. 2009. “Developing Narrative Competence in Medical Students.” Journal of Medical Ethics; Medical Humanities 35:54. https://doi.org/10.1136/jmh.2008.001354.

Publisher's Note Springer Nature remains neutral with regard to jurisdictional claims in published maps and institutional affiliations. 